Participatory Educational Research (PER)

Special Issue 2016-I, pp., 43-47; 01 January, 2016

Available online at http://www.partedres.com

ISSN: 2148-6123

http://dx.doi.org/10.17275/per.16.spi.1.5

\title{
Use of Cloud-Based Translation Management Systems in Translation Education
}

\author{
Sinem CANIM ALKAN * \\ Department of Translation Studies, Istanbul University, Istanbul, Turkey
}

\begin{abstract}
This is a study about the integration of translation technology in a course named Translation of Specific Fields IV given at the Division of Translation and Interpreting in English of Istanbul University. The educator of the course decided to make use of a 'cloud-based translation management system (TMS)'. The term can be defined as a translation management system where the translation memory system and all other resources for translation are hosted on a remote server and can be accessed via Internet. The purpose of study was to find out whether the use of this type of translation tool in translation courses can help students become self- and life-long learners and what advantages and disadvantages this practice can offer. For this purpose, the author made use of her observations on her own course practices. It was seen that cloud-based TMSs could easily be integrated in translation courses. Advantages are more than disadvantages. The advantages are not only for the students but also for educators and departments. These systems could be used in a way that contributes to self-learning and self-discovery skills of students.
\end{abstract}

Keywords: Cloud-based translation management systems, IT translation, technology integration, translation technology, translation education.

\section{Introduction}

This study is about the integration of translation technology in a course given at the Division of Translation and Interpreting in English of Istanbul University by the present author. The type of the integrated technology is cloud-based translation management system. These systems have been gaining popularity in the translation market since 2010. Cloudbased translation management system can very briefly be defined as a new generation of translation memory system or translation management system (TMS) based on the SaaS (software as a service) model (Zydron, 2012, p. 20). In SaaS model, software are supplied over the Internet as a service rather than installed on computers. In these systems, data is stored and processed on remote servers centrally. Local computer is used only for data entry and display using a standard Web browser (Muegge, 2011, p. 21). In order to use the system, all you need is a device with internet connection and browser. SaaS TMSs run on its providers' servers. The provider manages access to the application, including security, availability, and performance (Sales Force, https://www.salesforce.com/saas/, 3 September 2015). So what happens in the cloud stays in the cloud. Some examples of currently available

\footnotetext{
* Corresponding author: Sinem Canım Alkan (e-mail: $\underline{\text { scanim@istanbul.edu.tr })}$
} 
cloud-based TMSs are Motaword, Memsource Cloud, XTM Cloud, Wordbee, MateCat, Wordfast Anywhere, Google Translator's Toolkit and Lionbridge Translation Workspace.

Cloud-based TMSs have various benefits. First, there is no license fee. Instead you pay a monthly subscription fee or you don't pay any fee at all. They are maintenance free. Updates are made automatically. Multiple translators can work on the same file at the same time. Since they are internet-based, there is no need to install any software. Due to their browser based nature, they work on any device (desktop, laptop, tablet or smartphone). Finally, the user does not need to invest in high-tech computers with huge memories in order to use these systems. Considering these benefits and some other possible benefits, the present author decided to use this system in the course named Translation of Specific Fields IV.

The purpose of this study was to describe and analyze my use of a cloud-based TMS as an educator in a translation course in terms of advantages and disadvantages. My research questions were:

(1) Can the use of cloud-based TMSs in translation courses help students become selfand life-long learners?

(2) What advantages and disadvantages can using cloud-based TMSs in translation courses offer?

\section{Theoretical Framework}

The literature was reviewed to see what scholars think about the use of technology in translation education. There are various views about how technology should be integrated into translation education. The views that contributed to my point of view in this study were as follows:

(3) Translation technology should not be seen as an ultimate goal, but as a tool in teaching translation (Kiraly, 2000; Pym, 2003 and 2007; Bernardini, 2004; Enriquez-Raido, 2013; Canım Alkan, forthcoming).

(4) Translation technology can be used to help students improve such abilities as problem-solving, self-learning, self-discovery and using information effectively.

(5) Since technology training is related with skills rather than knowledge which should be practiced as much as possible, translation tools should ideally be used by students as much as possible, not only in a specific course that is dedicated to translation technology and isolated from other courses (Pym, 2013, p. 497; Enriquez-Raido, 2013, p. 277)

Although cloud-based TMSs have been used since 2010 (Zydron, 2012, p. 20), the academic research on the use of it in translation education is limited. Two scholars have studies on the topic. These are Vanessa Enriquez-Raido and Uwe Muegge.

According to Enriquez-Raido (2013), these systems are useful in helping students develop self-discovery and life-long learning skills (p. 280). Muegge (2012) thinks that they are useful and favorable tools due to their low cost and platform independency (p. 6). They require no specific operating system and they can be used any time and from any place that has an Internet connection, using any computing device (Muegge, 2013, p. 19). 


\section{Corpus and Methodology}

In the light of this theoretical framework, a course named Translation of Specific Fields IV which is offered in the Division of Translation and Interpreting in English of Istanbul University was analyzed in order to find answers to the research questions, which were given above. In the following section, the course was introduced very briefly and then the course practices were described.

\section{A case study on the use of cloud-based TMSs in translation education: Translation of Specific Fields IV}

Translation of Specific Fields IV is offered at the 8th semester of the BA program in the Division of Translation and Interpreting in English. It is selective. 32-34 students select the course every year. The course aims to introduce the field of information technologies (IT) and its terminology and help students gain translation experience in the field. The course was conducted at a computer lab with Internet connection. However, most of the computers were broken and the lab was not maintained by a technical staff.

A cloud-based TMS named MotaWord (www.motaword.com) was integrated in the course. Very briefly, it uses a cloud based translation platform and "the translators registered on the system are able to login simultaneously into projects that fit their language combination and provide translation service collaboratively - while also seeing the whole content for contextual purposes (https://www.motaword.com/about, 30 November 2015)".

The reasons for selecting this system were as follows:

(1) It is a cloud-based translation tool.

(2) It was offered to the educator and students of the course free of charge.

(3) Technical support was offered free of charge.

(4) Training was offered online and free of charge by the provider.

Since the tool was offered online with an SaaS model, the students needed to register as a translator on Motaword and create a user account using their email address and a password that they selected. In order to have their accounts activated, they had to attend a webinar of about 20 minutes on how to use the system. After the training they were sent a survey by email which included 10 questions about how to use the system. They answered the questions and e-mailed the answers to MotaWord. After the activation of all accounts, the students were assigned to a translation project. The project manager was the present author and the files to be included in the project were selected by her with the help of MotaWord staff. The files were provided also by the Motaword Company. The project included 1) preparing a style sheet and a term list, 2) translation and 3) editing.

\section{Findings and Discussion}

Our use of a cloud-based TMS provided a lot of advantages and some disadvantages. To begin with the advantages, the system can be used anywhere and anytime. This was a motivation factor to students for completing their assignments on time. Secondly, the students did not need to bring print-outs of their translations to the classroom for discussion. The style sheet, term list and any translation decision by any student could be seen by the educator and all of the students any time from any device with an Internet connection. As a third advantage, the students worked on the system using one shared translation memory and could see each other's translation decisions the moment a translation unit is entered in the translation 
memory database. By this way, they experienced how TMSs contribute to consistency in translation. On the other hand, they also saw that careless use of translation memories might cause low quality translations. No money was invested and a little time was spent for migrating to a new technology. Students gained hands-on experience with a new type of translation technology which is gaining more and more popularity. They had the chance to apply their theoretical knowledge in an actual translation project.

Students improved their self-discovery and self-learning skills. They learnt how to use the system by themselves. They saw that there are other sources of information in learning how to use a new technology. They watched a webinar, read some documents about MotaWord, and when necessary they did search about their specific technical problems. They saw that learning a new technology was not a big deal.

As for the disadvantages, three were observed. Firstly, the students were unable to download their translations into their personal computers. Only the educator with an administrative account could do so. This was a limitation posed by the nature of the system. Secondly, students were unable to use the system when there is no Internet connection or a central technical problem on the system. This is an intrinsic disadvantage of all cloud-based systems. Term list and style sheet could only be updated by the educator since she was provided with an administrative account by the MotaWord Company.

\section{Conclusion}

It can be inferred from this study that cloud-based TMSs could easily be integrated in translation courses. Advantages are more than disadvantages. The advantages are not only for the students but also for educators and departments. These systems could be used in a way that contributes to self-learning and self-discovery skills of students, which is a positive answer to the essential question of the study which was given earlier in this paper as question number 1 .

This study suggests that translation educators should make use of technology as much as possible in as many courses as possible. Technology use should not be limited to a course dedicated to the teaching of translation technology. It is hoped that more educators will make use of translation and language technologies and share their experiences with their colleagues. This way they can benefit from each other's experiences. Translation educators should encourage students to learn new technologies by themselves and help them overcome their worries about technology. They should let translation students encounter problems and try to solve these problems by themselves. By this way, students can practice and improve their problem-solving skills.

As a final note, this is a case study. It is not intended to serve as a best practice. But hopefully it has given or will give an idea to the educators willing to integrate technology into their translation courses.

\section{Acknowledgements}

I would like to thank all members of MotaWord Company for their contributions to this study. This study was supported by the Istanbul University Research Fund (project no. 57053). 


\section{References}

Bernardini, Silvia (2004) "The theory behind the practice: Translator training or translator education?" in Malmkjær, Kirsten (ed.) Translation in Undergraduate Degree

Programmes, Amsterdam/Philadelphia: John Benjamins Publishing Company, p. 17-29.

Canım Alkan, Sinem (forthcoming) "Lisans Düzeyinde Çeviri Eğitiminde Teknoloji Eğitiminin Yeri”, I.Ü. Çeviribilim Dergisi-I.U. Journal of Translation Studies, 4(7).

Kiraly, Donald (2000) A Social Constructivist Approach to Translator Education, Manchester: St. Jerome.

Marta Chereshnovska (2013). "Training for technical translators: an interview with Uwe Muegge". Available at: http://works.bepress.com/uwe_muegge/82

MotaWord, www.motaword.com

Muegge, Uwe (2011) "Teaching computer-assisted translation in the cloud: a down-to-earth model", International Federation of Translators (FIT) XIX World Congress. San Francisco. August 2011. Available at: http://works.bepress.com/uwe muegge/57

Muegge, Uwe (2012) "Cloud-based translation memory tools are changing the way translators work and train", The Big Wave of Language Technology 1.3. Available at: http://works.bepress.com/uwe muegge/76

Pym, Anthony (2003) "Redefining Translation Competence in an Electronic Age. In Defence of a Minimalist Approach" Meta: Translators' Journal, 48(4), p. 481-497.

Pym, Anthony (2007) "Translation technology and training for intercultural dialogue: What to do when your translation memory won't talk to you'. Available at: http://usuaris.tinet.cat/apym/on-line/translation/2007_tm_talk_to_me.pdf

Pym, Anthony (2013) "Translation Skill-Sets in a Machine-Translation Age" Meta: Translators' Journal, 58(3), p. 487-503.

Sales Force, https://www.salesforce.com/saas/, 3 September 2015

Zydron, Andrzej, "Cloud computing, SaaS and translation tools", Multilingual, JanuaryFebruary 2012, p. 20-21. 